\title{
Intelligent Nanoscale Dematerialized Manufacturing
}

\author{
Dalvinder Singh Grewal* \\ Department of English, India \\ *Corresponding author: Dalvinder Singh Grewal, Department of English, Ludhiana, India \\ Submission: 海 January 08, 2018; Published: 監January 11, 2018
}

\section{Editorial}

In the event of rising costs, increasing space and labour problems and demand for increasing accuracies for higher qualities, future industry needs intelligent nanoscale dematerialized manufacturing. The machine builders need to change manufacturing from currently producing heavy, long-delivery-time and high-energy-consuming machines to tailored combinations of extremely light-weighted, nonstiff, skeletal and low-environmental-impact machines integrated with appropriate total life-cycle services based on innovative winto-win business models with intelligent manufacturing [1]. The digital thread unites the life stages of a manufactured product, from design to production to field use basing in nanoscales.

Dematerialization is a new key strategy for innovation and is the ability to make things smaller. With the development of nanotechnology going on yo manufacturing tables, we can reduce the amount of material it takes to build the things we use, subtracting atoms from them even as we improve their capacity and performance [1].

The computer which soars in speed and memory even as it shrinks in size, is itself a microcosm of modern technology. I remember having seen the first computer in ONGC India office in Assam. It occupied a large room along with its cooling system. But now the computers, among other devices, are getting smaller, lighter, more portable, more economical and softer in environmental impact. Laptops used to be several inches thick and weigh six or seven pounds; today they use a fraction of the material and accomplish far more than their earlier versions and cost far less. The future computers are likely to be tiny wearable, low energy consuming but far speedier and multi-problem solving.

A few years before the hospitals used surgical tool that was the size of a trunk. The same tool was dematerialized down to the size of a cigarette pack with the exact same functionality. A fraction of the size manufactured with a fraction of the cost to manufacture and to ship is thus the future need. Lowered price can make it affordable to the lowest strata, expanding the market and the availability of a powerful tool.

The trend toward dematerialization is being primarily driven by energy intensive material processing increasing continuously increasing costs; increasing competition from substitute lighter materials with superior qualities like lower mass, low cost, higher strength and improved functions; replacing materials with saturated markets e.g., cement, steel, cars, consumer materials etc., change in user requirements with new materials [2].

Similarly dematerialization trend for automobiles involves the use of lightweight, high-strength alloys, and synthetics as substitutes for steel and cast iron. Large weight and size reductions were achieved by materials substitutions in the 1970s in order to conserve energy [3]. One pound of aluminum typically replaces two pounds of conventional metals, resulting in dramatic weight savings without compromising safety [4]. Aluminum has one-third the density of steel.

Nanotechnologyhasplayedaverymajorrolein dematerialization. In the last several years, multibillion-dollar markets based on nanotechnology have been developed. For example, in the United States, IBM has developed magnetic sensors for hard disk heads; Eastman Kodak and 3M have produced nanostructured thin-film technologies; Mobil has synthesized nanostructured catalysts for chemical plants, and Merck has produced nanoparticle medicines. Toyota has fabricated nanoparticle reinforced polymeric materials for cars in Japan, and Samsung Electronics is working on a flatpanel display with carbon nanotubes in Korea [5]. Novel materials are being marketed, such as for spectacles with scratch-resistant nano-coatings or sunburn lotions containing ultraviolet-absorbing nanoparticles [6].

Broadly speaking, nano-technology is the act of purposefully manipulating matter at the atomic scale i.e., nano-scale. For construction of nano-materials there is no dearth of atoms and molecules in universe. The only requirement is of assembling these atoms with required qualities. The nano-materials have the promise of providing strength many times more than steel; are flexible and portable; occupying negligible space; near nil transportable costs, construction costs and time; assuring safety and strength and causing no pollution [7]. Thus nanotechnology will help increasing strength, reduce space requirements and improve quality while digitalisation will help improve speed, accuracy and quality and reduce labour requirements. 
How can the required material be created? Material creation may involve all or some of the following steps:

a. Listing out characteristic requirements for the particular material

b. Identifying or Planning for innovating materials with the above characteristics

c. Adopting methods and approaches for material preparation

d. Organizing construction process and equipment

e. Construction, testing and try out and modification

f. Bulk production and

g. Using the materials for construction

For example the characteristic requirements for building construction are security, strength, easy and cheap transportability and flexibility, less labour and easy availability at affordable costs. The alternative materials providing these qualities are; diamond \& steel that provide security and strength; plastics, silicon, cardboard, paper and ply that provide easy transportability and flexibility, cheaper costs and less labor.

None of the materials in the world at present meets all the above needed qualities. Hence there is a need for innovation of such materials which contain all or almost all these qualities. One type of such novel material at the threshold or being developed is through nano-materials. Nano-materials are the materials with structured components with at least one dimension less than $100 \mathrm{~nm}$. Overall properties of all materials are determined by their structure at the micro \& nano-scale. Novel materials can be created by rearranging atomic structures [7].

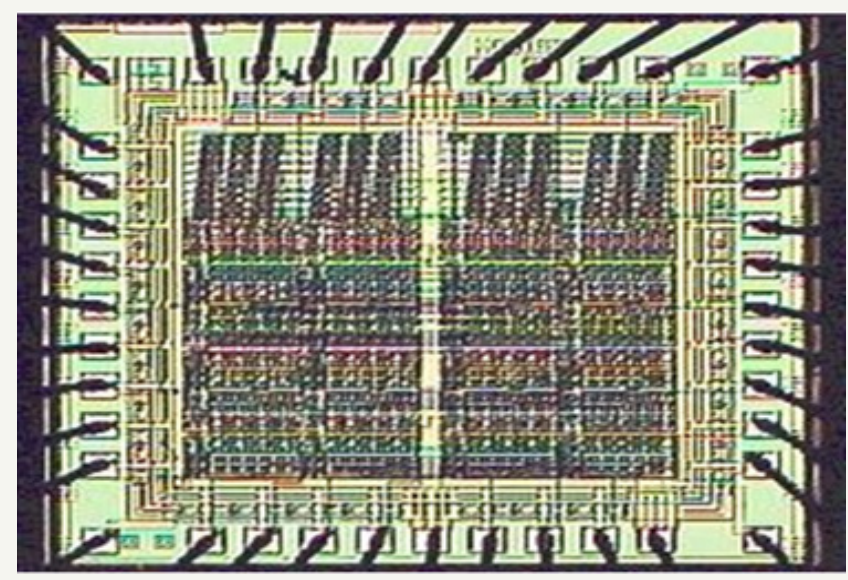

Figure 1: Arranging Atoms to make nano-materials.

Variations in the arrangement of atoms have distinguished the cheap from the cherished and the light from heavy. Arranged one-way, atoms make up soil, air, and water; arranged another way, they make up ripe strawberries. Arranged one way, they make up homes and fresh air; arranged another way, they make up ash and smoke. Nature which created coal, diamonds, sand and dust is the best guide to provide the suitable alternative materials for construction purposes as well. Nano-materials are prepared from nano-particles taking a cue from the nature. At the nano-scale, the bulk approximations of Newtonian physics are revealed for their inaccuracy, and give way to quantum physics [7] Figure 1.

The ability to synthesize nanoscale building blocks with precisely controlled size and composition and then to assemble them into larger structures with unique properties and functions has the potential to revolutionize segments of the manufacturing industry.

Applications include

a. Manufacturing of nanostructured metals, ceramics and polymers at exact shapes without machining

b. Improved printing brought about by nanometer-scale particles that have the best properties of both dyes and pigments

c. Nanoscale cemented and plated carbides and nanocoatings for cutting tools, electronic, chemical, and structural applications

d. New standards for measurements at nanoscale

e. Nanofabrication on a chip with high levels of complexity and functionality [7].

The developed nanocomposite materials from stainless steel and polymer by using multi-walled carbon nanotubes (MWCNT), is found to be many times stronger because the strength is 10100 times higher than the strongest steel. Grain refinement down to $100 \mathrm{~nm}$ of stainless steel and dispersion of nanostructured materials into the steel matrix increase superbly their mechanical properties.. The refined microstructure of 326L stainless steel in the treated layer led to increase in hardness, strength, and wear resistance. Nano-composites from steel and polymers are developed as stronger materials to withstand the impact of bullets and bombs. Polymers or steel are melted in a crucible/ mould of desired shape of bunker, command posts walls, helmets, bullet-proof jackets, etc can be developed easily. Carbon nanotubes dispersed in the melted polymer and steel followed by quenching up to room temperature provide an easiest technique to yield the nano-composites materials. Nano-composites dispersed with carbon nanotubes (diameter 25$50 \mathrm{~nm}$ ) in polymers and steel enhance tensile strength, hardness and higher temperature resistance. Stronger polymers also provide observation from inside for the purpose of observation and fire. The properties imparted by nanoparticles are varied and focus particularly on strengthening the tensile strength, hardness and barrier properties to temperature, gases and liquids as well as the possible improvement of fire behavior [8].

Concept of dematerialized manufacturing involves machine builders conceive machines as combinations of easily exchangeable modules consisting of ultra-light and adaptive skeletal structures occupying minimal space and operated digitally. These skeletal structures will be designed considering structure, control strategies and processes in an integral way with the aim of satisfying the functional requirements and of assuring the optimal global robustness and reliability of the machine breaking the link between 
production results and the material structure of machines and will reduce the total-life-cycle impacts and costs of machines in a radical manner. Then, by integrating dematerialised machines with other similar machines, innovative business models and total-life-cycle services, machine builders will be able to realize Dematerialised Manufacturing Systems with customised flexibility [1].

It includes lean manufacturing and services covering current research, best practices and future trends within the areas of global competitiveness and rapidly advancing technologies in flexible automation, information management, and intelligent manufacturing [9].

While dematerialization is frequently applied to consumer end products and production processes, it could be equally applicable in non-manufacturing fields such as agriculture. Reduction of pesticide use per unit crop, for example, dematerializes food production. It is also worth recognizing that the similar concept of producing equal units of energy while releasing less carbon as a result of fossil fuel combustion, commonly referred to as "decarbonization" is increasingly considered an important subclass of dematerialization

Manufacturing today must adjust to dynamic markets which demand excellence in areas of cost, quality, throughput, innovativeness, and time to market. Manufacturing companies must master emerging and rapidly advancing technologies in order to remain competitive. They are challenged to achieve short product development cycles, expand product lines, and combat shrinking product life cycles in a global economy marked by rapid fluctuations and increasing competitions [9].

This holistic approach for designing, producing and intelligent nanoscale dematerialized manufacturing integrated with total-life cycle services will coin a new concept in the manufacturing sector: Intelligent nanoscale dematerialized manufacturing solutions, will pave the way for transforming the machine-tool industry into a Knowledge-based, Competitive, Sustainable and Value-Adding sector [10]. The current nanoscale fabrication techniques such as vacuum deposition, which is used to deposit atoms in substrates below atmospheric pressure, are limited in terms of speed and the quality and the ability to scale to nano dimension.

Assessment of different spatial scales: from the product and process level to the company and sector level are needed to effectively assess the benefits of dematerialization strategies. There is also a need to assess the pollution, wastes, energy requirements, and natural resource requirements within each scale. Such a critical analysis looks not only at the amount of natural resources contained in assessed commodities and products, but also the hidden flows which are involved in producing them. Assessing the entire life cycle of a product can help to understand the systemic effects of different materials in different applications and the quantities of material inputs, thus providing information on the direct and indirect efficiencies of resource use [11].

\section{References}

1. Daniel Burrus (2013) Dematerialization-A pathway for innovation. Huffpost.

2. www.bfi.org/gbn_ecology.pdf

3. http://www.steel.org/media/

4. http://phe.rockefeller.edu/dematerialization/

5. http://www.memagazine.org/contents/current/features/frontier/ frontier.html

6. http://future.sri.com/Explorer/NT.shtml

7. Dalvinder SG (2014) Saving space from buildings by nanotechnology. IOSRJEN 4(2): 39-48

8. Dalvinder SG (2015) Super strong nano-composite materials for bunkers \& command posts. Army Nanotechnology Congress \& Expo,Frankfurt, Germany.

9. Roco MC (2013) Scientists are building the next generation of atomicscale devices, Atomic Toolbox: Manufacturing at the Nanoscale, Scientific American, USA.

10. Farhad Nabhani (2009) Proceedings of the $19^{\text {th }}$ International conference on flexible automation and intelligent manufacturing. FAIM, Teesside University, Middlesbrough, UK.

11. Penn IT (2001) Web-based survey of trends in dematerialization, Report No. CSS01-17, A report of the Center for Sustainable Systems, Center for Sustainable Systems, University of Michigan, USA. 